\title{
The Effects Of The Business Cycle On Oligopoly Coordination: Evidence From The U.S. Aluminum Industry
}

David I. Rosenbaum, University of Nebraska-Lincoln Sheng-Ping Yang, Black Hills State University

\begin{abstract}
Haltiwanger and Harrington (1991) among others explore a theoretical study on the effects of demand fluctuations on the degree of oligopoly coordination. They specify that demand movements are deterministic as the assumption of independent, identically distributed demand shocks in each period is excluded. This paper empirically examines the hypothesis implied by the Haltiwanger and Harrington in which current prices and margins vary directly with expected future demand. We also explore the time series properties of demand shocks. Various lag structures are introduced into the estimation. The model is applied to the U.S. aluminum industry. Results support the predictions of the theoretical models.
\end{abstract}

\section{INTRODUCTION}

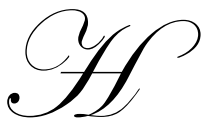

altiwanger and Harrington (1991) among others explore a theoretical study on the effects of demand fluctuations on the degree of oligopoly coordination. They relax the assumption of independent, identically distributed (i.i.d.) demand shocks from Rotemberg and Saloner's model (1986) by allowing demand to follow a deterministic cycle in which both the level of demand and the expected direction of demand are allowed to change over time. The model indicates that an important factor influencing the incentive to cheat is the projected future path of demand. Consequently, they find that current prices and margins respond to expected demand and that firms behave most competitively in the early stages of a recession.

The major difference between the Rotemberg and Saloner model and the Haltiwanger and Harrington model, as indicated by Gallet and Schroeter (1995), is the assumption about the time series properties of the demand shocks. With the i.i.d. assumption, Rotemberg and Saloner (1986) constrain all expected future demands to be equivalent and assume that current demand realizations (i.e. either positive or negative shocks) generate no effects on expected future demands. Therefore, in any period, a high (low) observed demand increases (decreases) the temptation to cheat on a previously sustainable collusive price while leaving the expected loss from retaliation unchanged. As each shock is observable at the beginning of the period, firms can revise the price countercyclically just enough to equate the incentive to deviate from the static expected loss from retaliation and reach a new sustainable collusive price. ${ }^{1}$

Hatiwanger and Harrington's (1991) revision specifies that demand movements are deterministic as the assumption of i.i.d. demand shocks in each period is excluded. Thus, a boom in their interpretation is when demand is increasing, which is different from Rotemberg and Saloner's assumption that a boom is when the level of demand is abnormally high (or the i.i.d. shock is positive). And, firms' expectations on future demand are no longer

\footnotetext{
${ }^{1}$ By constructing a model with i.i.d. demand shocks, Rotemberg and Saloner (1986) contend that price wars are most likely to take place during periods of unexpectedly high demand, and therefore, it is most profitable for firms to deviate on a previously sustainable collusive price when a shock pushes demand above its expected level. This leads to a countercyclical pricing.
} 
independent of current demand. This intertemporal relationship influences the incentives and deterrents to cheat on a collusive agreement. While current demand may be relatively high, if expected future demand is even higher, it creates a disincentive to cheat. Conversely, when current demand is falling, the deterrent is reduced and cheating becomes more likely. Therefore, fixing the current demand function, there is a greater incentive to deviate just before or during a recession than during an expansion. The implication of their model is that profits should rise during the initial periods of a boom, but should peak before the cycle. An alternative way of making this point is to say that profits should lead the demand cycle.

Empirical investigations on the dynamics of collusive pricing have been somewhat mixed and inconclusive. ${ }^{2}$ Borenstein and Shepard (1996) empirically investigate pricing behavior over the business cycle in retail gasoline markets. Their study deviates from the theoretical models in two respects. Marginal cost, which is assumed to be constant in both the Rotemberg and Saloner and the Haltiwanger and Harrington models, is allowed to vary over time. Another adjustment from the theoretical models is the length of the punishment period. In theory, punishments are infinite so that all future periods are relevant in forming a sustainable collusive price. For convenience in empirical estimation, Borenstein and Shepard assume that only the next period is relevant in influencing price.

Moreover, standard multi-period oligopoly models find that collusion is sustainable when the current gain from cheating on a non-cooperative price is just outweighed by the expected future punishment from deviation. Borenstein and Shepard assert that future punishments depend on expected future demand and expected future marginal costs. As expected demand increases or expected costs decrease, the future cost of cheating increases. Hence, a higher current margin is supportable. As a result, there is a link between current margins and expectations about future demand and costs. In their words, "controlling for demand, margins will respond positively to increases in near-term demand... [and] controlling for current input prices, margins will respond negatively to expected increases in input prices." (pp. 432-433)

On the whole, Borenstein and Shepard generate expected demand and cost by imposing a vector autoregression (VAR) process which is closely related to Haltiwanger and Harrington's theoretical modeling. ${ }^{3}$ They allow expected future marginal costs to affect margins by allowing input price changes to create predictable shifts in marginal costs. ${ }^{4}$ Their results match their predictions in which current margins increase with expected next period demand and decline with expected next period input prices. Hence, prices tend to be procyclical rather than countercyclical.

The empirical work in this paper is a symmetric version of Borenstein and Shepard except that seasonal patterns and cross-sectional effects are excluded from the model. ${ }^{5}$ Following Borenstein and Shepard's work we impose a revision that marginal cost is not held constant. In spite of the distinct attribute from retail gasoline markets, the hypothesis from Borenstein and Shepard is considerately pertaining to the U.S. aluminum industry within the VAR framework implied by the first degree Markov process. With aluminum ingot as a major input for manufacturing, the industry still attained some extend of relatively inelastic demand, at least in the short run, as do retail gasoline markets.

\footnotetext{
${ }^{2}$ Ellison (1994) tests the collusive stability of the Joint Executive Committee based on the Rotemberg and Saloner predictions with revision of the first order autocorrelation on the demand shocks. He models the collusive price as the ratio of current to future demand and composes a Markov structure as a determinant of the probability with which a price war begins. No obvious support is found in his model for the hypothesis that price wars occur during booms.

${ }^{3}$ Empirical estimation of expected demand and cost in their VAR construction is equivalent to the theoretical Markov process imposed in the Bagwell and Staiger's (1997) study, where only the present values of the variables are relevant for predicting the future.

${ }^{4}$ In Staiger and Wolak' (1992) study on price-setting supergames with capacity constraints, they explain that constant marginal cost may not be able to capture the role of capacity constraints that is central to the conventional view of the relationship between collusive prices and business conditions.

${ }^{5}$ Unlike season cycle unveiled in retail gasoline markets, aluminum demand fluctuates irregularly. Nevertheless, primary aluminum as a manufacturing input is generally ordered several months in advance. As a result, aluminum producers can approximately predict possible change in future demand and therefore decide the necessary adjustment of price margin.
} 
Section 2 contains a discussion of the structure of the U.S. aluminum industry. In section 3 the data are explained and preliminary results are derived. These results indicate that the lag structure and error correction technique may critically influence the results. Section 4 describes a further investigation into the lag structure and error correction. The results are presented in Section 5. Conclusions are described in Section 6.

\section{THE U. S. ALUMINUM INDUSTRY}

The structure of the U. S. aluminum industry changed after World War II as continuing relaxation of entry barriers and expansion of potential demand make the market to become more competitive. This altered the conventional operation in the market from one with Alcoa as leader to a more standard homogenous-good oligopoly despite the market price uniformity across producers with which Alcoa prevailed more often as the price leader (Mason, 1972). Correspondingly, several studies have shown that the degree of concentration in the industry only had a short-run effect on the price-cost margin after $1949 .^{6}$

In addition to the evolution on the market structure, ingot consumption in the aluminum industry has varied considerably over the post World War II period. This variation can be attributed to the general expansion of the economy and to the adoption of new applications, partially in response to real price decreases (Peck, 1961, p.31). The former generally occurred within short- and medium-run demand fluctuations, while the latter largely reflected the substitution between aluminum and other metal products and was seen as a longer-run dynamic fluctuation. ${ }^{7}$ The properties of aluminum have made it attractive in a wide array of end-use markets over the last five decades. It is light, resistant to corrosion, and provides good heat and electrical conductivity. Transportation, consumer durables, and industry machinery, among other products, are the three largest segments of demand.

Aside from the lucrative market atmosphere accelerating the growth of industry capacity, the interaction among the three leading firms as a rivalry has continuously led to an investment race in the industry. Though increasing capacity lowers the existing firm's marginal costs and makes the existing firms more effective competitors in the long run, excess capacity caused by short-run demand fluctuations also creates inventory accumulation. As producers intend to maintain production in times of slack demand rather than incur closing down and start-up costs, significant inventories at firm's level motive firms in price reduction. Consequently, accumulation of inventory caused by short-run demand fluctuation incurs the underlying reason that aluminum producers undercut current profits. ${ }^{8}$

\section{DATA EXPLORATION}

The data for the empirical estimation are based on census data as well as annual issues of Minerals Yearbook and are collected for the years 1949 through 1992. Descriptive statistics are presented in Table 1. Data on volume and value of primary ingot shipments, material costs, total payrolls, and production quantities throughout the sample period are used for estimating purposes. The transaction price is derived by dividing shipment value by shipment volume. Aluminum producers normally offer transportation discounts to customers instead of directly cutting the price when they try to push up sales. Therefore, the listed market prices may not obviously reflect the supply-demand equilibrium at any specific point in time. However, as indicated in Figure 1, the movement of derived prices approximately corresponds to that of the market list prices. Aluminum prices have remained relatively stable until the 1970s when the London Metal Exchange took effect on the list price of aluminum. As a

\footnotetext{
${ }^{6}$ See various investigations of the impact of concentration on performance in the U.S. aluminum industry over three different time terminals by Adams (1961), Froeb and Geweke (1987), and Yang (2005).

${ }^{7}$ Aluminum consumption varies because of manufacturers' shifts from one industrial material to another. Such transfers usually require modification of either the product or the production process, which, in turn, usually requires capital expenditures. Consequently, the switch between metals is not greatly influenced by short-run variations in the relative prices of the metals, implying that the short-run demand for aluminum is relatively price inelastic (Yang, 2005).

8 As pointed out in Scherer and Ross (1990, ch. 8), oligopolists operating evenly matched capital-intensive plants in cyclically sensitive, price-inelastic durable goods markets may, in the absence of institutions facilitating collusion, engage in especially bitter competition during recession.
} 
consequence, subsequent price fluctuation is likely to generate less unpredictable collusive result and yet greater incentive of deviation as depressing price margin occurs.

The main obstacle in estimating the price-cost margin is the unobserved marginal cost. Based on Haskel et al's (1995) approach, we define marginal cost as the increase in input costs arising from the change in output to estimate the mark-up from industry time series data. ${ }^{9}$ Expenses for labor, material, electric power and transportation compose the variable portions of total production cost for aluminum ingot, where labor and material costs make up about $60 \%$ of those variable costs. Accordingly, the costs of material and payroll are used as reasonable proxies for marginal cost [see Froeb and Geweke (1987) and Rosenbaum (1989)]. To calculate costs on a unit basis, total costs of material and payroll are divided by the volume of shipments. Transaction prices and material costs are deflated by the producer price index, while the consumer price index is used to deflate payroll cost. [see Sherer (1970, ch. 6)]

Ordinary least squares regression of margins on current production, next-period production, and current and next period payroll and materials costs is performed initially to explore the effects of the regressors. Next-period variables are estimated by assuming that producers form their expectations of future profit based on the VAR process, which will be explained in the next section. In equation (1), MARG is the margin in period $t, P R O D_{t}$ is production, $T W_{t}$ represents wages and the $T M_{t}$ is material cost.

$$
\begin{aligned}
\text { MARG }_{t}= & \alpha_{1}+\alpha_{2} \text { PROD }_{t+1}+\alpha_{3} P_{R O D_{t}}+\alpha_{4} T W_{t+1}+\alpha_{5} T W_{t} \\
& +\alpha_{6} T M_{t+1}+\alpha_{7} T M_{t}+\varepsilon_{l t}
\end{aligned}
$$

The resulting estimated coefficients are presented in the first column of Table 2 and are roughly consistent with the predictions of the theoretical models. Conditioning on contemporaneous quantity, current margin is an increasing function of next period's quantity. This result is consistent with the dynamic oligopoly literature. Current and expected payroll and material costs have a statistically insignificant impact on current margin.

The residuals from this regression exhibit first-order autocorrelation. The second column of Table 2 shows results correcting for first-order autocorrelation. They are similar to the uncorrected results, except that future wages $\left(T W_{t+1}\right)$ generate a negative but still insignificant coefficient.

As indicated by Peck, excess supply in the aluminum industry appears as an inevitable consequence of the demand function, the time lag in the construction of new capacity, and the existence of firms oriented toward longrun profit. The duration of the excess supply indicates that both production decisions and marginal costs may affect profit margins for several periods. In another attempt to eliminate the AR1, current and twice lagged-values of $\triangle P R O D_{t}=\left(P R O D_{t}-P R O D_{t-1}\right)$ and twice lagged-values of $\triangle T M_{t}$ and $\triangle T W_{t}$ are added to the regressors in equation (1). ${ }^{10}$ The results are presented in third column of Table 2 . Again, current margins are directly related to the next period production. Current margins are inversely related to the next period wages, as the theory predicts. However, they are directly related to the next period material costs, including these lag structures does not eliminate the AR1 process. The fourth column of Table 2 shows results when the standard AR1 correction is used. The effects of all of the next period variables persist but the coefficient on future production is statistically weaker. In all, Table 2 indicates that the results depend on the specification of the lag structure and may depend on the error correction method. The next section explores both topics more fully.

\footnotetext{
${ }^{9}$ Aluminum industry is a highly capital intensive industry in which the unit costs of material as well as labor are most likely to vary with output change. In such a case, the costs of material and labor are suited to be the proxy of the marginal cost.

${ }^{10}$ The standard errors of $\Delta T M_{t-3}$ and $\Delta T W_{t-3}$ are very noisy and greatly disturb the regression estimated, so both are dropped from the equation.
} 


\section{FURTHER ESTIMATION}

The results from the preliminary regressions suggest that the specification of the lag structure of transaction price response might have important effects in explaining margins. Therefore, two different models of the lag process are estimated. In order to obtain the expected values of quantity and costs, VAR processes are constructed modeling the production and cost variables as functions of various lag variables. The following three equations are used for the rolling regression technique in confirming the consistencies of the coefficients over time.

$$
\begin{aligned}
& \text { PROD }_{t}=\alpha_{1}+\alpha_{2} \text { PROD }_{t-1}+\alpha_{3} M P_{t-1}+\alpha_{4} D_{U R O_{t-1}}+\alpha_{5} I_{R O N} N_{t-1} \\
& +\alpha_{6} T I M E_{t}+\mu_{l t} \\
& T W_{t}=\beta_{1}+\beta_{2} \Delta T W_{t-1}^{+}+\beta_{3} \Delta T W_{t-2}^{+}+\beta_{4} \Delta T W_{t-1}+\beta_{5} \Delta T W_{t-2} \\
& +\beta_{6} \Delta L A B O R_{t-1}^{+}+\beta_{7} \triangle L A B O R_{t-2}^{+}+\beta_{8} \triangle L A B O R_{t-1}^{-} \\
& +\beta_{9} \triangle L A B O R_{t-2}^{-}+\beta_{10} T W_{t-1}+\beta_{11} L_{A B O R_{t-1}}+\beta_{12} \text { TIME }_{t}+\mu_{2 t} \\
& T M_{t}=\delta_{1}+\delta_{2} \Delta T M_{t-1}^{+}+\delta_{3} \Delta T M_{t-2}^{+}+\delta_{4} \Delta T M_{t-1}+\delta_{5} \Delta T M_{t-2} \\
& +\delta_{6} \Delta M E T A L_{t-1}^{+}+\delta_{7} \Delta M E T A L_{t-2}^{+}+\delta_{8} \Delta M E T A L_{t-1}^{-} \\
& +\delta_{9} \Delta M E T A L_{t-2}^{-}+\delta_{10} T M_{t-1}+\delta_{11} M E T A L_{t-1}+\delta_{12} T_{I M E_{t}}+\mu_{3 t}
\end{aligned}
$$

In equation (2), current production is modeled as a function of the lag values of production, transaction price $(M P)$, an index of durable goods manufacture $(D U R O)$, a price index of iron and steel $(I R O N)$, and the current value of a time variable $(T I M E)$. Since aluminum ingot is used primarily in durable goods manufacturing, the inclusion of DURO accounts for the changes in consumption attributable to changes in the current level of economic activity. TIME is added to capture other time-related exogenous changes in demand, as well as costs modeled more specifically in equations (3) and (4). The current transaction price may also be a function of current demand. However, in order to predict the expected demand correctly based on the lagged information, any current variable is not appropriately included in the model.

The equations for input costs are constructed analogous to the VAR model for transaction price, ${ }^{11}$ where the full lag structure is applied to involve all possible information. In equation (3), current payroll cost is dependent on changes in payroll cost $(\triangle T W)$, changes in a labor cost index $(\triangle L A B O R)$, the previous payroll cost, an index of labor cost $(L A B O R)$, and the time variable. In equation (4), the current material cost is based on changes in material costs $(\triangle T M)$, changes in metal product price index $(\triangle M E T A L)$, transaction cost's own lag value, the lag value of the price index for metal products $(M E T A L)$, and the time variable. The + superscript denotes an increase and the - a decrease in the variables. The $R^{2}$ of these predicting equations are between $80 \%$ and $95 \%$. From these three equations, the expected values of $P R O D, T W$ and $T M$ are generated.

With generated expected values substituted for future values, the regression estimating the current margin as a function of the anticipated values of demand and costs can be constructed as:

$$
\begin{aligned}
& M A R G_{t}=\alpha_{1}+\alpha_{2} E\left(P R O D_{t+1}\right)+\alpha_{3} P R O D_{t}+\alpha_{4} E\left(T M_{t+1}\right)+\alpha_{5} T M_{t} \\
& +\alpha_{6} E\left(T W_{t+1}\right)+\alpha_{7} T W_{t}+\alpha_{8} \Delta P R O D_{t}+\alpha_{9} \Delta P R O D_{t-1} \\
& +\alpha_{10} \Delta P R O D_{t-2}+\alpha_{11} \Delta T M_{t}+\alpha_{12} \Delta T W_{t}+v_{l t}
\end{aligned}
$$

where $\mathrm{E}(\bullet)$ is the expectations operator.

Regarding the long lag effect in the aluminum industry, equation (5) may be too parsimonious to satisfactorily explain margins. A standard approach to estimation in the presence of lagged responses is still to model price as a VAR process in which the current change in price is a function of past shocks and an errorcorrection term that takes into account the underlying structural relationship. That is, a more complicated equation

\footnotetext{
${ }^{11}$ The complete procedure of the VAR model is expressed in equation (6) through (10).
} 
may be modeled with transaction prices, and, therefore, margins, as a function of contemporaneous and lagged changes in production, payroll and material costs, transaction prices, and an error-correction term involving the oneperiod lags of transaction price, production, and costs of payroll and materials.

Regarding the concern outlined above, equation (6) is first constructed to capture the essence of Haltiwanger and Harrington's model, in which the direction of price change is dependent on the direction of current and lagged demand changes, marginal cost changes and lagged price changes. The number of lag periods has been chosen to allow for a longer-than-expected response lag.

$$
\begin{aligned}
T P_{t}-T P_{t-1} & =\alpha_{1}+\alpha_{2} \Delta P R O D^{+}{ }_{t}+\alpha_{3} \Delta P R O D^{+}{ }_{t-1}+\alpha_{4} \Delta P R O D^{+}{ }_{t-2} \\
& +\alpha_{5} \Delta P R O D_{t}^{-}+\alpha_{6} \Delta P R O D_{t-1}^{-}+\alpha_{7} \Delta P R O D_{t-2}^{-}+\beta_{1} \Delta T M^{+}{ }_{t} \\
& +\beta_{2} \Delta T M^{+}{ }_{t-1}+\beta_{3} \Delta T M_{t}+\beta_{4} \Delta T M_{t-1}+\beta_{5} \Delta T W^{+}+\beta_{6} \Delta T W_{t-1}^{+} \\
& +\beta_{7} \Delta T W_{t}+\beta_{8} \Delta T W_{t-1}+\beta_{9} \Delta T P^{+}{ }_{t-1}+\beta_{10} \Delta T P_{t-1}^{-}+v_{2 t}
\end{aligned}
$$

Next, the error-correction terms including lagged transaction price, production, and payroll and material costs are incorporated into the model:

$T P=\gamma_{0}+\gamma_{1} P R O D+\gamma_{2} T M+\gamma_{3} T W$

According to equation (7), the extent to which prices deviate from equilibrium in period t-1 would be expected to be:

$T P_{t-1}-\gamma_{0}-\gamma_{1} P R O D_{t-1}-\gamma_{2} T M_{t-1}-\gamma_{3} T W_{t-1}$

If the next-period margin adjusts toward the equilibrium by some factor $\delta(0>\delta>-1)$, the error-correction effect for period t would be $\delta\left(T P_{t-1}-\gamma_{0}-\gamma_{1} P R O D_{t-1}-\gamma_{2} T M_{t-1}-\gamma_{3} T W_{t-1}\right)$, which can be rewritten as

$\delta T P_{t-1}-\delta \gamma_{0}-\delta \gamma_{1} P R O D_{t-1}-\delta \gamma_{2} T M_{t-1}-\delta \gamma_{3} T W_{t-1}$

Substituting equation (9) into equation (6), an extended model with error-correction effects can be generated as in equation (10).

$$
\begin{aligned}
& T P_{t}-T P_{t-1}=\eta_{1}+\alpha_{2} \Delta P R O D^{+}{ }_{t}+\alpha_{3} \Delta P R O D_{t-1}^{+}+\alpha_{4} \Delta P R O D_{t-2}^{+} \\
& +\alpha_{5} \Delta \mathrm{PROD}_{t}^{-}+\alpha_{6} \Delta \mathrm{PROD}_{t-1}^{-}+\alpha_{7} \Delta \mathrm{PROD}_{t-2}^{-}+\beta_{1} \Delta \mathrm{TM}_{t}^{+} \\
& +\beta_{2} \Delta T M_{t-1}^{+}+\beta_{3} \Delta T M_{t}^{-}+\beta_{4} \Delta T M_{t-1}^{-}+\beta_{5} \Delta T W_{t}^{+}+\beta_{6} \Delta T W_{t-1}^{+} \\
& +\beta_{7} \Delta T W_{t}+\beta_{8} \Delta T W_{t-1}+\beta_{9} \Delta T P_{t-1}^{+}+\beta_{10} \Delta T P_{t-1}^{-}+\beta_{11} T P_{t-1} \\
& +\alpha_{8} \text { PROD }_{t-1}+\beta_{12} T M_{t-1}+\beta_{13} T W_{t-1}+v_{2 t}
\end{aligned}
$$

where $\eta_{1}=\alpha_{1}-\delta \gamma_{0}, \alpha_{8}=-\delta \gamma_{1}, \beta_{11}=\delta, \beta_{12}=-\delta \gamma_{2}$, and $\beta_{13}=-\delta \gamma_{3}$.

Adding $T P_{t-1}$ and subtracting $T M_{t-1}$ and $T W_{t-1}$ from both sides of equation (10), the price-cost margin can be obtained on the left-hand side. Subtracting $T M_{t-1}$ and $T W_{t-1}$ from the right-hand side of (10) requires subtracting one from the coefficients on $\Delta T M^{+}{ }_{t}, \Delta T M_{t}, \Delta T W^{+}, \Delta T W^{+}{ }_{t}$. The first two contain a positive $T M_{t}$ while the last two contain a positive $T W_{t}$. Additionally, $\Delta T M^{+}{ }_{t}$ and $\Delta T M_{t}^{-}$contain a negative $T M_{t-1}$ while $\Delta T W_{t}^{+}$and $\Delta T W_{t}$ contain a negative $T W_{t-1}$. Therefore, subtracting each from the coefficient on $T M_{t-1}$ and $T W_{t-1}$ re-generates the current changes. The result is presented in equation (11).

$$
\begin{aligned}
\text { MARG }_{t}= & \eta_{1}+\alpha_{2} \Delta \operatorname{PROD}^{+}{ }_{t}+\alpha_{3} \Delta \operatorname{PROD}^{+}{ }_{t-1}+\alpha_{4} \Delta P R O D^{+}{ }_{t-2} \\
& +\alpha_{5} \Delta \operatorname{PROD}_{t}^{-}+\alpha_{6} \Delta P R O D^{-}{ }_{t-1}+\alpha_{7} \Delta P R O D_{t-2}^{-}+\left(\beta_{1}-1\right) \Delta T M^{+}{ }_{t} \\
& +\beta_{2} \Delta T M^{+}{ }_{t-1}+\left(\beta_{3}-1\right) \Delta T M_{t}^{-}+\beta_{4} \Delta T M_{t-1}^{-}+\left(\beta_{5}-1\right) \Delta T W^{+}{ }_{t} \\
& +\beta_{6} \Delta T W^{+}{ }_{t-1}+\left(\beta_{7}-1\right) \Delta T W_{t}+\beta_{8} \Delta T W_{t-1}+\beta_{9} \Delta T P^{+}{ }_{t-1} \\
& +\beta_{10} \Delta T P_{t-1}^{-}+\left(\beta_{11}+1\right) T P_{t-1}+\alpha_{8} P R O D_{t-1}+\left(\beta_{12}-1\right) T M_{t-1} \\
& +\left(\beta_{13}-1\right) T W_{t-1}+v_{2 t}
\end{aligned}
$$


Augmenting equation (11) by taking into account the effect of expected demand and costs creates the basic estimating equation (12).

$$
\begin{aligned}
\text { MARG }_{t}= & \eta_{1}+\alpha_{2} \Delta P R O D^{+}{ }_{t}+\alpha_{3} \Delta P R O D^{+}{ }_{t-1}+\alpha_{4} \Delta \operatorname{PROD}^{+}{ }_{t-2} \\
& +\alpha_{5} \Delta P R O D_{t}^{-}+\alpha_{6} \Delta P R O D_{t-1}^{-}+\alpha_{7} \Delta P R O D_{t-2}^{-}+\left(\beta_{1}-1\right) \Delta T M^{+}{ }_{t} \\
& +\beta_{2} \Delta T M^{+}{ }_{t-1}+\left(\beta_{3}-1\right) \Delta T M_{t}+\beta_{4} \Delta T M_{t-1}^{-}+\left(\beta_{5}-1\right) \Delta T W^{+} \\
& +\beta_{6} \Delta T W^{+}{ }_{t-1}+\left(\beta_{7}-1\right) \Delta T W_{t}+\beta_{8} \Delta T W_{t-1}+\beta_{9} \Delta T P^{+}{ }_{t-1} \\
& +\beta_{10} \Delta T P_{t-1}^{+}+\left(\beta_{11}+1\right) T P_{t-1}+\alpha_{8} P R O D_{t-1}+\left(\beta_{12}-1\right) T M_{t-1} \\
& +\left(\beta_{13}-1\right) T W_{t-1}+\alpha_{9} E\left(P R O D_{t+1}\right)+\beta_{14} E\left(T W_{t+1}\right) \\
& +\beta_{15} E\left(T W_{t+1}\right)+v_{2 t}
\end{aligned}
$$

A further step to test endogeneity may be required to prevent bias in the coefficients. Expected demand is reasonably a function of transaction price and, therefore, a function of the transaction margin. Anticipated payroll and material costs also may have a possible influence on the current margin. Therefore, the Hausman test is performed to test the potential endogeneity of these exogenous variables. The results from the tests reveal that only quantity variables are correlated with the error term in the model. None of the cost variables are functions of the current margin.

In order to correct the biased coefficients from the endogeneity of quantity variables, a two-stage leastsquares (2SLS) procedure is applied for consistent estimates for these equations. That is, the fitted values of anticipated and current quantities for equation (5) and the fitted value of anticipated quantity for equation (12) must be found by constructing a set of instrument variables. The rational instruments include the time variable, current and lag values of the production index of durable goods manufacture, the price index of iron and steel, and real GNP.

\section{ESTIMATION RESULTS}

The OLS and two-stage least-squares estimates of equations (5) and (12) are reported in Table 3. In all specifications, the coefficient on expected quantity is positive, as the Haltiwanger-Harrington hypothesis predicts, and significantly different from zero at the 5\% significance level or better. Current margins are increasing in expected demand. Using the coefficients from 2SLS estimation of equation (12), the elasticity of the margin with respect to expected next-period quantity is about .94 at mean margin and quantity. The signs of the coefficients for expected payroll costs are also consistent with the Haltiwanger-Harrington hypothesis but are insignificant in both equations. This may be due to the fact that the aluminum industry is so capital intensive. (Boyd et al., 1995) The coefficients of expected material costs are significant only in equation (5). However, the positive coefficients contradict the Haltiwanger-Harrington hypothesis.

The regression results show that expectations about future demand exhibit a stronger effect on current margin than expectations about future marginal costs. According to Adams (1961, ch. 6), the importance of the constancy of short-run marginal and average variable costs for pricing purposes is that variations in demand and the resulting changes in output of primary aluminum will not affect the level of mill operating costs per pound of metal. This aspect of production costs has had an important effect on the pricing policies of the integrated producers in primary aluminum. Average costs as well as marginal costs of primary aluminum remain relatively constant over the business cycle. This seems to be consistent with the result that only expected demand has significant effects on current margin.

Figure 2 graphs the effects of demand changes on margins over a recent twenty-year period. ${ }^{12}$ Margins are estimated by the coefficients of the production variables from equation (12). The estimated margin and production are then normalized by their own means. Since the marginal cost is excluded in estimating the margins, Figure 2 shows solely the response of margins to changes in demand. Although the result is not as obvious as the case of

\footnotetext{
${ }^{12}$ After 1970 the industry grows more competitive and less oligopolistic. At the same time, the industry's oversupply problem appeared to be ended.
} 
retail gasoline markets with seasonal pattern, the margin pattern in Figure 2 is roughly consistent with the prediction that margins peak before, but near the peak of demand. The margin peak in 1978 is just before the production peak in 1980. The margin peaks in 1982 and 1990 are near the respective demand peaks in 1984 and 1991. This is consistent with the theoretical predictions.

\section{NON-COLLUSIVE EXPLANATIONS OF FUTURE DEMAND AND COST}

Procyclical prediction which is implied by the collusive pricing theory might involve the effect of noncollusive reaction to demand fluctuations. Aluminum is a highly durable goods used as input for other manufactures. With possible accumulation of inventory, manufactures anticipating higher demand and prices next period should demand more in the current period at relative lower prices. Consequently, current price increases with intention of predicting future higher prices and accumulating current inventory. Non-collusive actions simply correspond to the result of collusive pricing actions.

The action of accumulating inventory is also likely taken by primary aluminum producers when higher cost in primary aluminum production is anticipated. That is, producers may choose to increase current output and thereby increase inventory when future production cost is expected to be higher and therefore profit margin is expected to be lower. By doing so, producers would have to lower price in order to stimulate current market demand to reduce compiled inventory. Accordingly, an anticipation of higher cost tomorrow may induce a lower current price.

In the primary aluminum industry, the aspect of constant short-run marginal cost generates the endogenous attribute of short-run inventory changes. Inventory change is mainly due to the change of market demand with producers' intention to keep full-capacity level of output. As a result, current inventory change is affected by current demand variation rather than future demand expectation given constant level of output. As predicted future demand change is based on current demand change, an anticipation of higher demand tomorrow is likely related to a lower current inventory and therefore higher price. Again, the result is consistent with collusive pricing prediction. The empirical result shows the evidence corresponding to this characteristic.

In addition, the attribute of constancy of short-run marginal costs generally induces no expectation for nearterm change in marginal cost. As marginal cost remains constant in the short run, current margin change should not ascribe to the change of expected near-term changes of marginal costs. Hence, changes in collusive margins respond solely and positively to anticipated changes in demand given constant marginal costs in the short run.

\section{CONCLUSION}

Haltiwanger and Harrington explore a theoretical study on the effects of demand fluctuations on the degree of oligopoly coordination. They relax the assumption of independent, identically distributed (i.i.d.) demand shocks from Rotemberg and Saloner's model by allowing demand to follow a deterministic cycle in which both the level of demand and the expected direction of demand are allowed to change over time. The model indicates that an important factor influencing the incentive to cheat is the projected future path of demand. Consequently, they find that current prices and margins respond to expected demand and that firms behave most competitively in the early stages of a recession.

This paper empirically estimates the hypothesis implied in the Haltiwanger-Harrington in which expected demand has a positive effect and expected marginal cost has a negative impact on current margins. Data from the U.S. aluminum industry show that margins respond to expected demand with the sign predicted by Haltiwanger and Harrington. This result holds under a variety of specifications and for various error correction techniques. Payroll and material costs present relatively inconsistent results with respect to theoretical predictions. In all, the model shows some support for the hypothesis that oligopoly margins tend to peak prior to demand. 


\section{REFERENCES}

1. Adams, Walter, The Structure of American Industry, The Macmillan Co., New York, New York, 1961.

2. Bagwell, Kyle and Robert W. Staiger, Collusion over the Business Cycle, RAND Journal of Economics, Vol. 28, No. 1, pp. 82-106, 1997.

3. Blinder, Alan S., Can the Production Smoothing Model of Inventory Behavior Be Saved, Quarterly Journal of Economics, Vol. 101, No. 3, pp. 431-453, 1986.

4. Borenstein, Severin and Andrea L. Shepard, Dynamic Pricing in Retail Gasoline Markets, RAND Journal of Economics, Vol. 27, No. 3, pp. 429-451, 1996.

5. Boyd, Roy G., Chulho Jung, and Barry J. Seldon, The Market Structure of the US aluminum Industry, Journal of Economics and Business, Vol. 47, No. 3, pp. 293-301, 1995.

6. Ellison, Glenn, Theories of Cartel Stability and the Joint Executive Committee, RAND Journal of Economics, Vol. 25, No. 1, pp. 37-57, 1994.

7. Froeb, Luke and John Geweke, Long Run Competition in the U.S. Aluminum Industry, International Journal of industrial organization, Vol. 5, No. 1, pp. 67-78, 1987.

8. Fudenberg Drew and Eric S. Maskin, The Folk theorem in Repeated Games with Discounting or with Incomplete Information, Econometrica, Vol. 54, No. 3, pp. 533-554, 1986.

9. Gallet, Craig A. and John R. Schroeter, The Effects of the Business Cycle on Oligopoly Coordination: Evidence from the U.S. Rayon industry, Review of Industrial Organization, Vol. 10, No. 2, pp. 181-196, 1995.

10. Greene, W.H., Econometric Analysis, $2^{\text {nd }}$ ed., Macmillan Co., New York, New York, 1993

11. Haltiwanger, John and Joseph E. Harrington, Jr., The Impact of Cyclical Demand Movements on Collusive Behavior, RAND Journal of Economics, Vol. 22, No. 1, 89-106., 1991.

12. Haskel, Jonathan, Christopher Martin, and Ian Small, Price, Marginal Cost and the Business Cycle, Oxford Bulletin of Economics and Statistics, Vol. 57, No. 1, pp. 25-41, 1995.

13. Maddala, G. S., Introduction to Econometrics, $2^{\text {nd }}$ ed., Macmillan Co., New York, New York, 1992.

14. Mason, Tim W. The Effects of Entry: A Study of the American Aluminum Industry, unpublished Ph.D. dissertation, University of Pittsburgh, 1972.

15. Peck, Merton J., Competition in the Aluminum Industry: 1945-1958, Harvard University Press, Cambridge, Massechusett, 1961.

16. Rosenbaum, David I., An Empirical Test of the Effect of Excess Capacity in Price Setting, CapacityConstrained Supergames, International Journal of Industrial Organization, Vol. 7, No. 2, pp. 231-241, 1989.

17. Rotemberg Julio J. and Garth Saloner, A Supergame-Theoretic Model of Price Wars during Booms, American Economic Review, Vol. 76, No. 3, pp. 390-407, 1986.

18. Scherer, Frederic M., Industrial Market Structure and Economic Performance. Rand McNally \& Co., Chicago, Illinois, 1970.

19. Scherer, Frederic M. and D. Ross, Industrial Market Structure and Economic Performance, Houghton Mifflin Co., Boston, Massachusetts, 1990.

20. Staiger, Robert W. and Frank A. Wolak, Collusive Pricing with Capacity Constraints in the Presence of Demand Uncertainty, RAND Journal of Economics, Vol. 23, No. 2, pp. 203-220, 1992.

21. The Commerce Department, Economics Bulletin Board, University of Michigan, Ann Arbor, Michigan, various years.

22. U.S. Bureau of the Census, Current Industrial Reports, Government Printing Office, Washington, DC, various years.

23. U.S. Bureau of the Census, , Statistical Abstract of the United States, Government Printing Office, Washington, DC, various years.

24. U.S. Department of the Interior, Minerals Yearbook, Government Printing Office, Washington, DC, various years.

25. U.S. President Council of Economic Advisers, Economic Report of the President, Government Printing Office, Washington, DC, various years. 
26. Yang, Sheng-Ping, Market Power and Cost Efficiency: the Case of the U.S. Aluminum Industry, Resources Policy, Vol. 30, No. 2, pp. 101-106, 2005.

Table 1: Descriptive Statistics (44 Observations)

\begin{tabular}{lcccc}
\hline \multicolumn{1}{c}{ Variable } & Mean & $\begin{array}{l}\text { Standard } \\
\text { Deviation }\end{array}$ & Minimum & Maximum \\
\hline $\begin{array}{l}\text { Transaction Price (TP) } \\
\text { (cents per short ton) }\end{array}$ & 10.98 & 3.02 & 5.70 & 15.50 \\
$\begin{array}{l}\text { Transaction Cost of Payroll (TW) } \\
\text { (cents per short ton) }\end{array}$ & 1.57 & .54 & .67 & 2.65 \\
$\begin{array}{l}\text { Transaction Cost of Material (TM) } \\
\text { (cents per short ton) }\end{array}$ & 6.37 & 1.30 & 3.85 & 8.25 \\
$\begin{array}{l}\text { Quantity of Production (PROD) } \\
\text { (millions short tons) }\end{array}$ & 3.19 & 1.38 & .60 & 5.13 \\
$\begin{array}{l}\text { Expected Cost of Payroll (EXP TW) } \\
\text { (cents per short ton) }\end{array}$ & 1.58 & .55 & .69 & 2.64 \\
$\begin{array}{l}\text { Expected Cost of Material (EXP TM) } \\
\text { (cents per short ton) }\end{array}$ & 6.48 & 1.14 & 3.85 & 8.01 \\
$\begin{array}{l}\text { Expected Quantity of Production (EXP PROD) } \\
\text { (millions short tons) }\end{array}$ & 2.81 & 1.22 & .53 & 4.53 \\
$\begin{array}{l}\text { Transaction Margin (MARG) } \\
\text { (cents per short ton) }\end{array}$ & 3.04 & 1.51 & .57 & 5.38 \\
\hline
\end{tabular}

Table 2: Preliminary Regressions (Dependent Variable: MARG $_{t}$ )

\begin{tabular}{|c|c|c|c|c|}
\hline & OLS & OLS-AR1 & OLS & OLS-AR1 \\
\hline PROD $_{t}$ & $-.856(.455)^{\mathrm{c}}$ & $.467(.343)$ & $-1.506(.348)^{\mathrm{a}}$ & $-1.173(.390)^{\mathrm{a}}$ \\
\hline PROD $_{t+1}$ & $.958(.466)^{\mathrm{b}}$ & $.737(.313)^{\mathrm{b}}$ & $1.228(.363)^{\mathrm{a}}$ & $.647(.336)^{c}$ \\
\hline $\mathbf{T W}_{\mathrm{t}}$ & $1.523(2.025)$ & $-.477(1.433)$ & $3.563(1.690)^{\mathrm{b}}$ & $3.631(1.663)^{\mathrm{b}}$ \\
\hline $\mathbf{T W}_{t+1}$ & $-.639(1.975)$ & $-2.021(1.489)$ & $-3.923(1.833)^{\mathrm{b}}$ & $-4.389(1.811)^{b}$ \\
\hline $\mathbf{T M}_{\mathrm{t}}$ & $.177(.507)$ & $.326(.360)$ & $-.046(.375)$ & $-.123(.392)$ \\
\hline $\mathbf{T M}_{\mathrm{t+1}}$ & $.394(.482)$ & $.581(.344)^{\mathrm{c}}$ & $.900(.400)^{\mathrm{b}}$ & $1.002(.387)^{\mathrm{a}}$ \\
\hline$\triangle$ PROD $_{\mathrm{t}}$ & & & $-2.097(.433)^{\mathrm{a}}$ & $1.866(.453)^{\mathrm{a}}$ \\
\hline$\triangle$ PROD $_{t-1}$ & & & $1.481(.381)^{\mathrm{a}}$ & $1.154(.373)^{\mathrm{b}}$ \\
\hline$\triangle \mathrm{PROD}_{\mathrm{t}-2}$ & & & $1.052(.390)^{\mathrm{a}}$ & $.743(.360)$ \\
\hline$\Delta \mathrm{TW}_{\mathrm{t}}$ & & & $-3.147(1.708)^{\mathrm{c}}$ & $-2.266(1.681)$ \\
\hline$\Delta \mathrm{TW}_{\mathrm{t}-1}$ & & & $-1.224(1.683)$ & $.235(1.519)$ \\
\hline$\Delta \mathbf{T M}_{\mathrm{t}}$ & & & $.250(.410)$ & $.111(.396)$ \\
\hline$\Delta \mathbf{T M}_{\mathrm{t}-1}$ & & & $-.015(.404)$ & $-.297(.377)$ \\
\hline Constant & $-2.395(1.163)^{b}$ & $-16.09(11.16)$ & $-1.585(1.158)$ & $-.058(2.300)$ \\
\hline$\rho$ & & $.988(.041)$ & & $.614(.186)$ \\
\hline $\mathbf{R}^{2}$ & .560 & .797 & .852 & .890 \\
\hline Observations & 44 & 44 & 44 & 44 \\
\hline
\end{tabular}

Notes: Standard error in parenthesis.

${ }^{\mathrm{a}}=$ Significant at $99 \%$ confidence level.

${ }^{\mathrm{b}}=$ Significant at $95 \%$ confidence level.

${ }^{c}=$ Significant at $90 \%$ confidence level. 
Table 3: Estimation of Equations (5) and (12) (Dependent Variable: MARG $_{t}$ )

\begin{tabular}{|c|c|c|c|c|}
\hline \multirow[b]{2}{*}{ Coefficient of } & \multicolumn{2}{|c|}{ Equation (5) } & \multicolumn{2}{|c|}{ Equation (12) } \\
\hline & OLS & 2SLS & OLS & 2SLS \\
\hline PROD $_{t}$ & $-1.414(.407)^{\mathrm{a}}$ & $-1.696(.343)^{\mathrm{a}}$ & & \\
\hline $\mathbf{E}\left(\mathbf{P R O D}_{t+1}\right)$ & $1.032(.355)^{\mathrm{a}}$ & $1.277(.358)^{\mathrm{a}}$ & $1.097(.464)^{\mathrm{b}}$ & $1.019(.503)^{\mathrm{b}}$ \\
\hline $\mathbf{T M}_{\mathbf{t}}$ & $-.201(.371)$ & $-.033(.295)$ & & \\
\hline $\mathbf{E}\left(\mathbf{T M}_{\mathrm{t+1}}\right)$ & $.780(.368)^{b}$ & $.838(.355)^{b}$ & $.792(.611)$ & $.796(.624)$ \\
\hline $\mathbf{T W}_{\mathrm{t}}$ & $1.092(1.616)$ & $-.608(1.366)$ & & \\
\hline$E\left(T W_{t+1}\right)$ & $-.793(1.100)$ & $-.397(1.156)$ & $-.513(1.490)$ & $-.473(1.507)$ \\
\hline$\triangle$ PROD $_{t}$ & $1.219(.422)^{\mathrm{a}}$ & $1.228(.345)^{\mathrm{a}}$ & & \\
\hline$\Delta \mathbf{P R O D}_{t-1}$ & $.780(.387)^{\mathrm{b}}$ & $.855(.332)^{b}$ & & \\
\hline$\triangle$ PROD $_{t-2}$ & $.345(.304)$ & $.433(.258)^{\mathrm{c}}$ & & \\
\hline$\Delta \mathbf{T M}_{\mathrm{t}}$ & $.060(.387)$ & $.033(.337)$ & & \\
\hline$\Delta \mathrm{TW}_{\mathrm{t}}$ & $-.911(1.704)$ & $-.520(1.522)$ & & \\
\hline$\Delta \mathrm{PROD}^{+}{ }_{\mathrm{t}}$ & & & $-1.711(.859)^{\mathrm{b}}$ & $-1.299(1.080)$ \\
\hline$\Delta \mathbf{P R O D}_{\mathrm{t}-1}^{+}$ & & & $.108(.946)$ & $.095(.957)$ \\
\hline$\Delta$ PROD $^{+}{ }_{t-2}$ & & & $-1.410(.863)$ & $-1.172(.940)$ \\
\hline$\triangle$ PROD $_{\mathrm{t}}^{-}$ & & & $-.327(.665)$ & $-.263(.678)$ \\
\hline$\Delta$ PROD $_{t-1}^{-}$ & & & $.490(.696)$ & $.386(.728)$ \\
\hline$\triangle$ PROD $_{t-2}^{-1}$ & & & $-.055(.722)$ & $-.012(.731)$ \\
\hline$\Delta \mathbf{T M}^{+}{ }_{\mathbf{t}}$ & & & $.670(.752)$ & $.648(.776)$ \\
\hline$\Delta \mathbf{T M}_{\mathrm{t}-1}^{+}$ & & & $.810(.750)$ & $.789(.763)$ \\
\hline$\Delta \mathbf{T M}_{\mathrm{t}}^{-}$ & & & $-.961(1.384)$ & $-1.406(1.408)$ \\
\hline$\Delta T M_{t-1}^{-}$ & & & $-1.488(.875)^{\mathrm{c}}$ & $-1.414(.884)$ \\
\hline$\Delta \mathbf{T W}^{+}{ }_{t}$ & & & $-4.129(3.269)$ & $-3.939(3.337)$ \\
\hline$\Delta \mathbf{T W}_{t-1}^{+}$ & & & $-2.679(3.477)$ & $-2.911(3.511)$ \\
\hline$\Delta \mathbf{T W}_{\mathrm{t}}^{-}$ & & & $1.568(4.029)$ & $1.996(4.098)$ \\
\hline$\Delta \mathbf{T} \mathbf{W}_{t-1}^{-}$ & & & $3.560(2.925)$ & $3.448(2.954)$ \\
\hline$\Delta \mathbf{T P}^{+}{ }_{t-1}$ & & & $-.035(.281)$ & $-.012(.286)$ \\
\hline$\Delta \mathbf{T} \mathbf{P}_{t-1}^{-1}$ & & & $.174(.367)$ & $.146(.373)$ \\
\hline $\mathbf{T P} \mathbf{t}_{\mathrm{1}-1}$ & & & $.466(.246)^{\mathrm{c}}$ & $.459(.250)^{\mathrm{c}}$ \\
\hline PROD $_{t-1}$ & & & $-1.312(.399)^{\mathrm{a}}$ & $-1.226(.430)^{\mathrm{a}}$ \\
\hline $\mathbf{T M}_{\mathrm{t}-1}$ & & & $-.547(.507)$ & $-.538(.516)$ \\
\hline $\mathbf{T W}_{\mathrm{t}-1}$ & & & $-.477(1.863)$ & $-.419(1.888)$ \\
\hline Constant & $.524(2.194)$ & $.128(1.483)$ & $-.972(2.186)$ & $-1.226(2.242)$ \\
\hline$\rho$ & $.634(.137)$ & $.407(.184)$ & & \\
\hline Observations & 39 & 39 & 39 & 39 \\
\hline $\mathbf{R}^{2}$ & .880 & .917 & .924 & .923 \\
\hline
\end{tabular}

Notes: Standard error in parenthesis.

${ }^{\mathrm{a}}=$ Significant at $99 \%$ confidence level.

${ }^{\mathrm{b}}=$ Significant at $95 \%$ confidence level.

${ }^{\mathrm{c}}=$ Significant at $90 \%$ confidence level. 
Figure 1: Aluminum Prices, 1949 - 1992

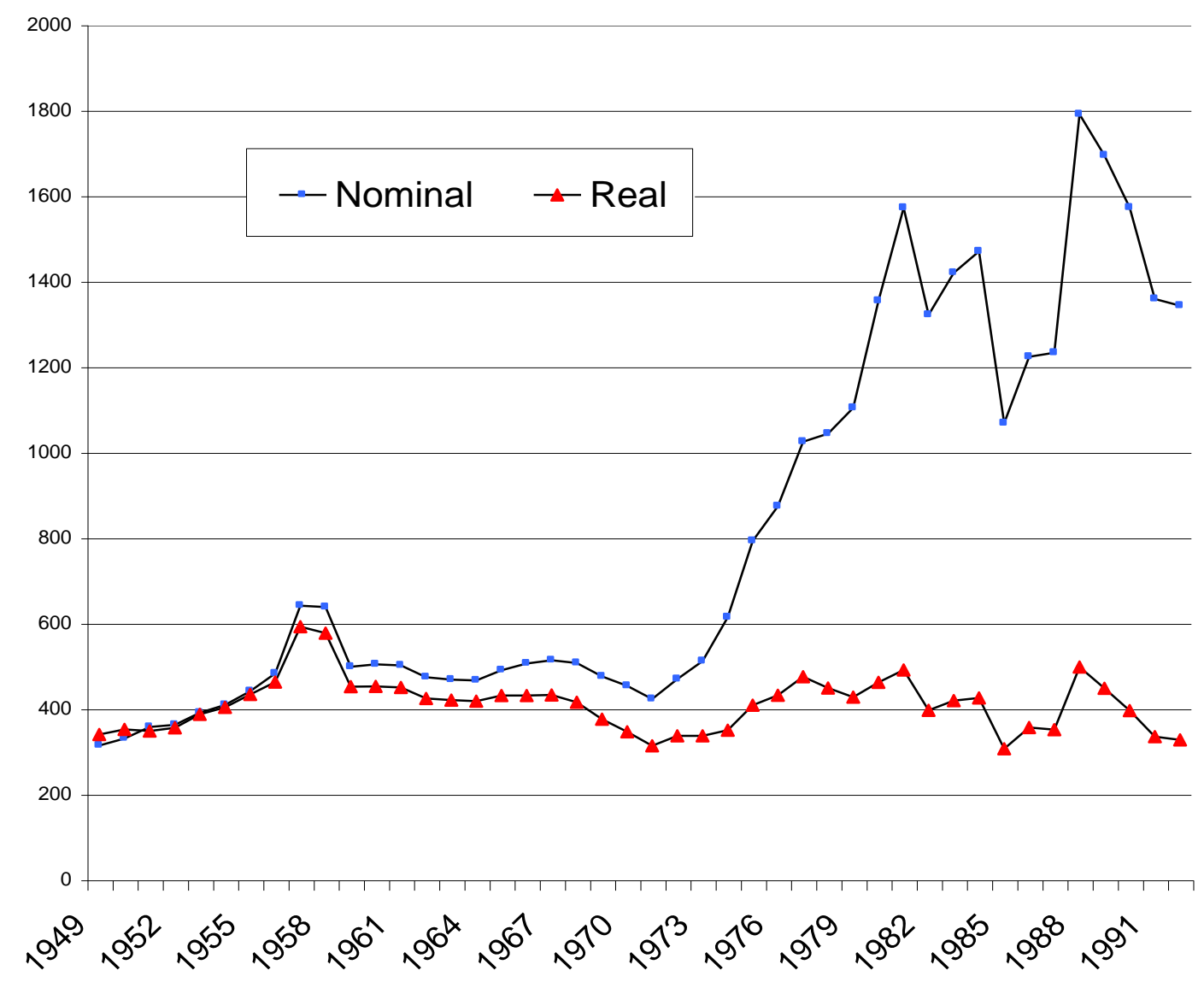

Figure 2: Estimated Effect of Demand on Margin

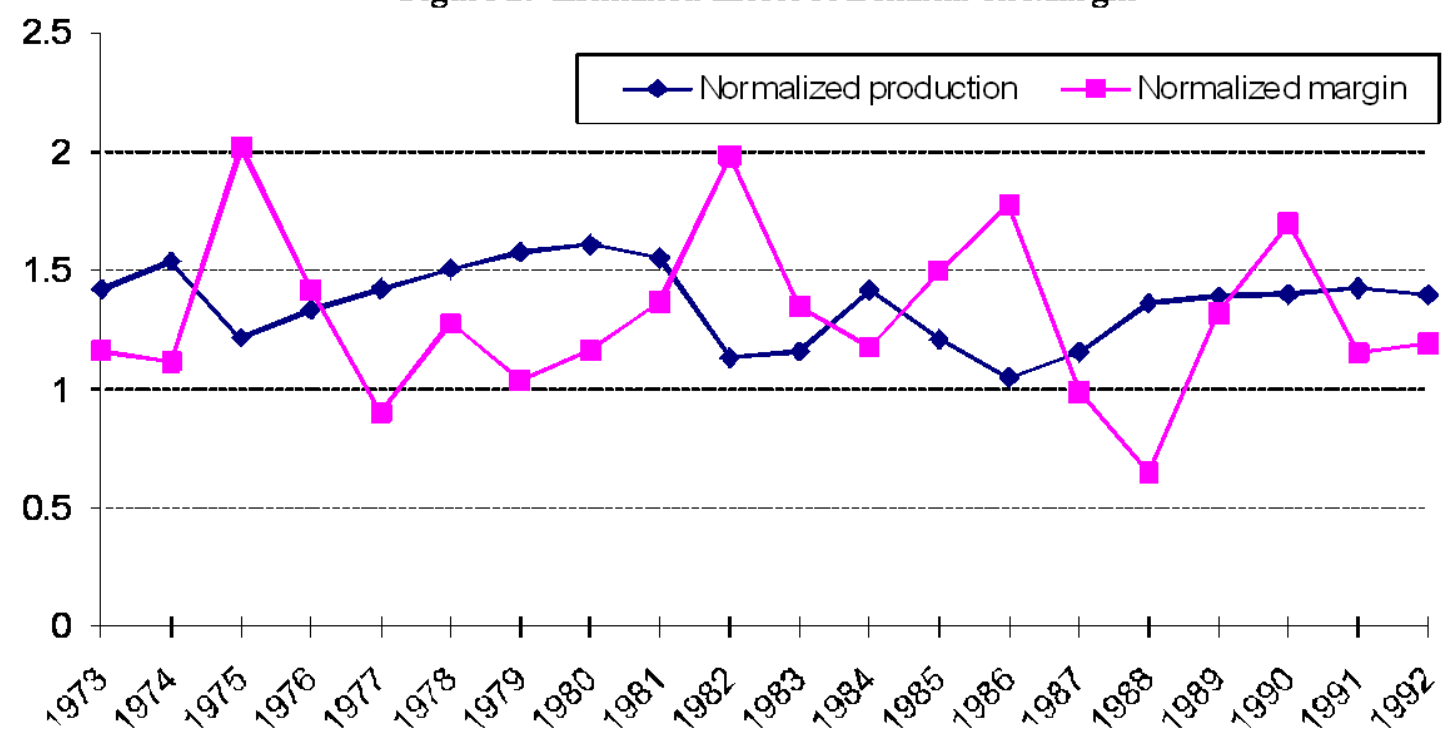

